\title{
VAREJO EM DESMATERIALIZAÇÃO: EXPERIÊNCIA DA LIVRARIA NAS DIMENSÕES FÍSICA E VIRTUAL
}

\author{
Dematerialization retail: Bookstore experience in physical and virtual dimensions \\ Desmaterialización del comercio minorista: Experiencia de librerías en las dimensiones física y virtual
}

Maria Silvia Moliterno Pena ${ }^{1}$ | msilviapena@gmail.com | ORCID: 0000-0003-0897-9113

Eliane Pereira Zamith Brito ${ }^{1}$ | eliane.brito@fgv.br | ORCID: 00oo-0002-7340-1337

${ }^{1}$ Fundação Getulio Vargas Escola de Administração de Empresas de São Paulo, São Paulo, SP, Brasil

\section{RESUMO}

O objetivo deste estudo é o entendimento do papel e da relevância da loja física no varejo contemporâneo em processo de desmaterialização. A literatura sugere que a loja física mantém a relevância no varejo integrado como lugar da experiência, entretanto não detalha, pela perspectiva do consumidor, o que determina a relevância e que experiências emergem da loja física. Partindo do conceito de cocriação da experiência por empresa e consumidor, verificamos que a experiência de cada consumidor é única e que a relevância da loja é determinada pelas características pessoais do consumidor. Identificamos os tipos de experiência que emergem da loja física e da loja virtual, e o papel da tecnologia no empoderamento do consumidor. Como contribuição gerencial, nosso estudo fornece subsídios para a gestão do varejo com dimensões física e virtuais integradas. Determinamos que, nas livrarias, segmento fortemente impactado pela desmaterialização, as características pessoais que determinam a relevância da loja física são relacionadas ao apreço pela leitura e apego ao mundo material, e as experiências que emergem da loja são Lugar de Compra, Garimpo, Portal da Magia e Refúgio do Lar. Os resultados são específicos do contexto, mas direcionam a análise da desmaterialização do varejo em geral.

PALAVRAS-CHAVE | Experiência do consumidor, loja física, loja virtual, desmaterialização, varejo integrado.

\section{ABSTRACT}

The aim of this study is to understand the role and relevance of the physical store in contemporary integrated retail. The literature suggests that physical store maintains its relevance as a place of experience; however, it does not detail, from the consumer's perspective, what determines relevance and which experiences emerge from the physical store. Based on the concept of experience co-creation, we argue that each consumer's experience is unique and that the relevance of the store is determined by the consumer's personal characteristics. We identified emergent experiences from physical and virtual stores and the role of technology in consumer empowerment. As a managerial contribution, our study provides direction for physical and virtual integrated retail management. We determined that, in bookstores, a segment strongly impacted by dematerialization, the characteristics that determine the relevance of the physical store are related to the appreciation for reading and the materiality attachment. The experiences that emerge from the store are Buying Place, Gold-Digging, Magical Portal and Home Refuge. Although the results are context specific, they can drive the analysis of retail dematerialization in general.

KEYWORDS I Consumer experience, physical store, virtual store, dematerialization, integrated retail.

\section{RESUMEN}

El objetivo de este estudio es comprender el papel y la relevancia de la tienda física en el comercio minorista contemporáneo en proceso de desmaterialización. La literatura sugiere que la tienda física mantiene su relevancia en el retail integrado como lugar de experiencia; sin embargo, no detalla, desde la perspectiva del consumidor, qué determina la relevancia y qué experiencias surgen de la tienda física. Partiendo del concepto de cocreación de la experiencia por empresa y consumidor, verificamos que la experiencia de cada consumidor es única y que la relevancia de la tienda está determinada por las características personales del consumidor. Identificamos los tipos de experiencias que surgen de la tienda física y de la tienda virtual y el papel de la tecnología en el empoderamiento del consumidor. Como aporte gerencial, nuestro estudio proporciona material para la gestión del retail con dimensiones físicas y virtuales integradas. Determinamos que, en las librerías, segmento fuertemente afectado por la desmaterialización, las características personales que determinan la relevancia de la tienda física están relacionadas con el aprecio por la lectura y el apego al mundo material, y las vivencias que emergen de la tienda son Lugar para Comprar, Minería, Portal Mágico y Refugio del Hogar. Los resultados son específicos del contexto, pero dirigen el análisis de la desmaterialización minorista en general.

PALABRAS CLAVE I Experiencia del consumidor, tienda física, tienda virtual, desmaterialización, retail integrado. 


\section{INTRODUÇÃO}

O varejo contemporâneo está em transformação, decorrente do processo de integração de suas dimensões física e virtual (Shankar, Inman, Mantrala, Kelley, \& Rizley, 2011; Verhoef, Kannan, \& Inman, 2015; Verhoef, Neslin, \& Vroomen, 2007) e da possibilidade de redução dos produtos a informações digitais (Denegri-Knott, Watkins, \& Wood, 2013; Lehdonvirta, 2012). Nesta nova realidade, a suposição é que a loja física mantém sua relevância como lugar da experiência (Gensler, Neslin, \& Verhoef, 2017; Shankar et al., 2011; Verhoef et al., 2015; Verhoef et al., 2007). No entanto, o número significativo de lojas físicas fechadas nos últimos anos (Coffman, 2018; Corkery, 2018; Rushe, 2017) indica ser necessário entender melhor, na perspectiva do consumidor, a experiência que manterá a relevância das lojas físicas.

A literatura sobre experiência do consumidor é abundante e estende o conceito para incorporar as mudanças trazidas pela tecnologia, entretanto não detalha a experiência na loja no contexto contemporâneo de desmaterialização de consumo. Como resultado, pouco sabemos sobre as diferenças de experiências que emergem das lojas física e virtual e os fatores que determinam a relevância da loja física. Nosso estudo explora essas questões, contribuindo para a literatura de experiência do consumidor aplicada ao varejo.

0 estudo foi conduzido no contexto de livrarias, que têm canal de vendas e produto desmaterializados. 0 estudo é qualitativo, interpretativo e exploratório, coletamos dados por meio de entrevistas fenomenológicas e observação participante e realizamos a análise ao longo da pesquisa de campo com lógica indutiva, verificando padrões emergentes dos dados em processo iterativo (Gill, 2014; Smith, Flowers, \& Larkin, 2009).

Identificamos quatro tipos de experiências que emergem da interação do consumidor com a livraria, determinadas pelas características pessoais do consumidor relacionadas a apreço pela leitura e apego à materialidade. Como contribuição gerencial, nosso estudo fornece subsídios para gestão de varejo integrado de livros, não sendo generalizáveis (Thompson, Locander, \& Pollio, 1989; Tracy, 2010), porém os achados do estudo podem direcionar reflexões sobre experiência do consumidor em outros segmentos do varejo em desmaterialização.

A seguir, detalhamos o referencial teórico do estudo, e na sequência explicamos a pesquisa realizada, apresentamos resultados de pesquisa e a discussão dos resultados.

\section{EXPERIÊNCIA DO CONSUMIDOR}

Há diversas definições de experiência relacionada a consumo na literatura, como experiência de marca (Schmitt, 2009), experiência do consumidor (Thompson et al., 1989), experiência do cliente (Pine \& Gilmore, 1998; Schmitt, Brakus, \& Zarantonello, 2015) e marketing de experiência (Schmitt, 2011), com entendimentos semelhantes de que experiência emerge das respostas multidimensionais, holísticas e subjetivas do consumidor às ofertas da firma (Lemon \& Verhoef, 2016) e que a experiência não é projetada e controlada pela empresa, mas dependente da contribuição do consumidor e cocriada nos pontos de contato, inclusive na loja (Arnould, 2005). Uma abordagem mais recente considera que, além de empresa e consumidor, a tecnologia também integra a relação que origina a experiência (Kozinets, 2019; Kozinets, Patterson \& Ashman, 2017), constituindo uma assemblage (DeLanda, 2006). A seguir, apresentamos uma visão histórica do conceito Experiência do Consumidor, mostrando o aumento da complexidade com a incorporação de tecnologia.

A concepção de experiência na literatura de marketing origina-se do reconhecimento de pessoas como seres dotados de sentimentos (Addis \& Holbrook, 2001; Holbrook, 2018; Lemon \& Verhoef, 2016). No início 
dos anos 1980, a visão de um consumidor guiado pela subjetividade (Hirschman \& Holbrook, 1982; Holbrook \& Hirschman, 1982) contrapõe-se à visão preponderante do consumidor racional e objetivo, baseada no pensamento da área de economia, e estabelece o conceito de experiência do consumidor como ferramenta para criar valor. Embora o artigo de Holbrook e Hirschman (1982) seja indicado como texto inaugural nas pesquisas sobre experiência do consumidor (Carù \& Cova, 2003), a literatura registra há muito tempo a importância do conceito (Holbrook, 2000, 2018).

Holbrook e Hirschman (1982) propõem entendimento do consumo hedônico pela combinação da cognição com as emoções (Babin, Darden, \& Griffin, 1994). As experiências eram caracterizadas como extraordinárias ou memoráveis, por terem significado emocional forte o suficiente para transformar o indivíduo (Carù \& Cova, 2003), e as publicações gerenciais utilizavam metáforas de show business (Schmitt, Rogers, \& Vrostsos, 2004) e teatro (Pine \& Gilmore, 1999) para caracterizar negócios com estratégia voltada à experiência. A experiência era apresentada como uma forma de diferenciação, encenada pela empresa para criar uma conexão emocional e memorável, levando ao engajamento do consumidor e à produção de valor, e garantindo lucratividade (Pine \& Gilmore, 1998, 1999). As práticas do show business são exemplos de criação de experiências significativas (Schmitt et al., 2004). A literatura posteriormente passou a entender que experiências emergem de todos os eventos de consumo (Holbrook, 2000) e podem ser extraordinárias ou ordinárias (Schmitt, 2009), positivas ou negativas (Holbrook, 2000, 2018) e apelam à subjetividade

A tecnologia tem transformado o consumo e a experiência do consumidor. Produtos são reduzidos a informações digitais (Lehdonvirta, 2012; Magaudda, 2011), ofertas são individualizadas por inteligência de dados (Linzbach, Inman, \& Nikolova, 2019), ambientes digitais proporcionam experiências totalmente virtuais (Denegri-Knott \& Molesworth, 2010; Denegri-Knott et al., 2013) e plataformas tecnológicas criam novos modelos de negócio (Bardhi \& Eckhardt, 2012; Belk, 2014). As experiências ganham ainda mais importância nesse consumo desmaterializado, baseado em acesso e efêmero (Bardhi \& Eckhardt, 2017), e a literatura passa a investigar o impacto da desmaterialização de consumo na experiência do consumidor, revelando diferentes percepções (Mardon \& Belk, 2018): o consumo mediado pela tecnologia energiza a experiência (Kozinets et al., 2017), a experiência proporcionada por espaços virtuais é superior (Denegri-Knott \& Molesworth, 2010) e os produtos digitais são valorizados (Mardon \& Belk, 2018), entretanto o valor atribuído a produtos físicos é maior que o valor atribuído a seus substitutos digitais (Atasoy \& Morewedge, 2018).

Estudos recentes tratam experiência como interconexão de humanos, objetos e máquinas (Hoffman \& Novak, 2017; Kozinets, 2019; Kozinets et al., 2017), utilizando a lógica da assemblage (DeLanda, 2006), e estabelecem que a experiência emerge também da interação de pessoas com objetos tecnológicos. Investigando o papel de objetos inteligentes nas assemblages de consumo, Hoffman e Novak (2017) propõem o conceito experiência de assemblage em que todos os componentes humanos e não humanos têm agência, da qual emergem múltiplas experiências sobrepostas, incluindo a experiência da assemblage do consumidor e a experiência da assemblage do objeto (Hoffman \& Novak, 2017).

Como vimos, a literatura acompanha as mudanças tecnológicas que levam à desmaterialização do consumo, identifica a integração das dimensões física e virtual do varejo e estabelece papéis para a loja virtual, como lugar de conveniência, e para loja física, como lugar da experiência (Verhoef et al., 2015), entretanto não identifica os tipos de experiência que emergem da loja e como se estabelece a relevância da loja física na perspectiva do consumidor. Este estudo contribui para esse entendimento. 


\section{MÉTODOS DA PESQUISA}

Conduzimos pesquisa de metodologia qualitativa, de natureza exploratória e abordagem fenomenológica, que busca a compreensão de um fenômeno a partir da experiência pessoal vivida, integrando as perspectivas dos participantes do estudo e as interpretações dos pesquisadores (Thompson et al., 1989), observando os critérios de qualidade de pesquisa qualitativa (Tracy, 2010). 0 desenho da pesquisa, a análise dos dados e a redação do artigo foram feitos por ambas as autoras do estudo, que, apaixonadas por livros e frequentadoras de livrarias, reconhecem que não há neutralidade em suas perspectivas. A coleta de dados foi feita pela primeira autora por meio de entrevistas semiestruturadas e observação participante, entre março e novembro de 2018.

Escolhemos livraria como contexto porque é um segmento bastante impactado pela desmaterialização do consumo, com versões digitais de canal de compras e produto, de modo que a jornada de consumo do livro pode ser percorrida em diferentes arranjos, combinando os ambientes físico e virtual. Visitamos oito livrarias com modelos de negócio diversos, loja de única e de rede, loja em shopping e de rua, lojas grandes e pequenas, com oferta ampla e com oferta especializada, fazendo observações pontuais, mas decidimos eleger a Livraria Cultura do Conjunto Nacional, em São Paulo, como suporte para coleta sistemática de dados porque seu amplo espaço físico atrai um público variado, abriga múltiplos usos, permite visitas prolongadas e pertence a uma rede de livrarias com presença digital consolidada, cujo comércio eletrônico, iniciado em 1994, é atualmente responsável por quase um terço das vendas (Almeida, 2017). A loja é a maior da rede em volume de vendas e, com 4.300 metros quadrados, abriga café e teatro para 168 espectadores (Livraria Cultura, 2017). A rede chegou a ter, em 2017, 30 lojas físicas com as marcas Cultura e Fnac (Livraria Cultura, 2017; Melo, 2018), mas está fechando as lojas não lucrativas (Giovanelli, 2016) e focando seus esforços no comércio eletrônico. Em outubro de 2018, a Livraria Cultura entrou em processo de recuperação judicial, e o plano de recuperação prevê maior ênfase no comércio eletrônico, mantendo poucas lojas físicas (Exame, 2018).

A observação participante foi feita em dias de semana e horários diferentes, para obter uma visão mais completa do contexto. Foram feitas 16 visitas com observação direcionada a regiões específicas da loja e 22 visitas para observação dos itinerários de clientes e vendedores dentro da loja, de 90 minutos de duração em média. Seguindo o conselho de Wallendorf e Belk (1989), foi feito um esforço consciente de olhar o conhecido como novidade ao observar o espaço físico, o percurso e a postura dos clientes ao caminhar pela loja, examinar estantes, folhear livros, conversar com vendedores, encontrar amigos e sentar para tomar café, ler ou mexer no celular. Durante as visitas, foram feitos registros fotográficos, complementando as descrições do observado, as reflexões, sentimentos e suposições (Wallendorf \& Brucks, 1993).

Foram conduzidas entrevistas de caráter fenomenológico para capturar as emoções e visões de mundo dos participantes (Arsel, 2017; Thompson et al., 1989), estruturadas com uma lista de temas formulada com base na teoria e liberdade para seguir o fluxo da conversa e explorar temáticas correlatas. Fizemos recrutamento por bola de neve, sem recompensa, e conduzimos as entrevistas em lugares sugeridos pelos participantes. Recrutamos novos entrevistados até ocorrer o esgotamento teórico, formando um grupo heterogêneo de 33 participantes. Solicitamos que 13 dos entrevistados fizessem um exercício de fotoelicitação, apresentando imagens que representassem suas experiências em livraria, e 10 realizaram a tarefa. As entrevistas duraram em média 42 minutos, foram gravadas em áudio, com o consentimento dos participantes, e transcritas, totalizando 178 páginas A4 em espaçamento simples. Para garantir sigilo, utilizamos pseudônimos inspirados pelo universo literário e escoIhidos, sempre que possível, pelos participantes. O perfil dos participantes é apresentado no Quadro 1; nas 
colunas Apreço pela leitura e Apego ao mundo material, o número de asteriscos indica a intensidade da característica: quanto maior, mais intensa.

\section{Quadro 1. Perfil dos participantes}

\begin{tabular}{|c|c|c|c|c|c|c|c|}
\hline$\#$ & Pseudônimo & Referência literária & $\begin{array}{l}\text { Apreço } \\
\text { leitura }\end{array}$ & $\begin{array}{c}\text { Apego } \\
\text { materialidade }\end{array}$ & Gênero & Idade & Profissão \\
\hline 1 & Alonso & Don Quixote da La Mancha & ** & ** & Masculino & 51 & Administrador \\
\hline 2 & Bento & Dom Casmurro & ** & $\star \star \star *$ & Masculino & 52 & Administrador \\
\hline 3 & Camilo & Camilo Castelo Branco & 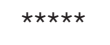 & 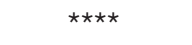 & Masculino & 55 & Consultor \\
\hline 4 & Clarice & Clarice Lispector & 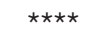 & $\star \star \star \star$ & Feminino & 23 & Designer \\
\hline 5 & Clarita & Clarita da Pá Virada & 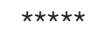 & ** & Feminino & 56 & Editora \\
\hline 6 & Elizabeth & Orgulho e Preconceito & $\star \star \star \star \star$ & 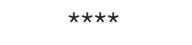 & Feminino & 46 & Administradora \\
\hline 7 & Emanuel & Corações Cicatrizados & 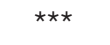 & 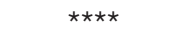 & Masculino & 51 & Empresário \\
\hline 8 & Emília & Sítio do Picapau Amarelo & 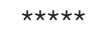 & $\star \star \star \star \star ~$ & Feminino & 53 & Advogada \\
\hline 9 & Fitz & Assassin Creed & $\star \star \star *$ & ** & Masculino & 22 & Designer \\
\hline 10 & Helga & O Perfume das Tulipas & $* \star * *$ & $\star \star \star *$ & Feminino & 55 & Escritora \\
\hline 11 & Hermione & Harry Potter & $\star \star \star *$ & ** & Feminino & 28 & Consultora \\
\hline 12 & Iracema & José de Alencar & $\star \star \star \star *$ & 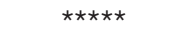 & Feminino & 69 & Psicoterapeuta \\
\hline 13 & Ítalo & Ítalo Calvino & 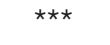 & 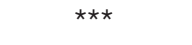 & Feminino & 27 & Designer \\
\hline 14 & Lúcia & Os Contos de Nárnia & 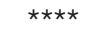 & ** & Feminino & 26 & Publicitária \\
\hline 15 & Melanie & Melanie Klein & 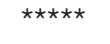 & 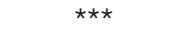 & Feminino & 48 & Psicóloga \\
\hline 16 & Michael & Trilogia Millenium & $\star \star$ & ** & Masculino & 22 & Designer \\
\hline 17 & Minny & The Help & 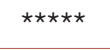 & $\star \star \star \star *$ & Feminino & 47 & Agente Viagens \\
\hline 18 & Myron & Harlan Cohen & $* * * *$ & ** & Feminino & 30 & Publicitária \\
\hline 19 & Narizinho & Sítio do Picapau Amarelo & ** & ** & Feminino & 18 & Estudante \\
\hline 20 & Nelson & Nelson Rodrigues & $* \star *$ & $* \star \star$ & Feminino & 51 & Advogado \\
\hline 21 & Perry & Erle Stanley Gardner & $* * \star *$ & ** & Masculino & 51 & Físico \\
\hline 22 & Poliana & Poliana & 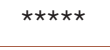 & 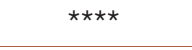 & Feminino & 50 & Nutricionista \\
\hline 23 & Príncipe & Pequeno Príncipe & $\star \star \star *$ & $\star \star \star *$ & Masculino & 27 & Designer \\
\hline 24 & Rubem & A Educação dos Sentidos & 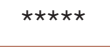 & ** & Masculino & 23 & Psicólogo \\
\hline 25 & Safira & Eragon & $* \star \star$ & $\star \star \star *$ & Feminino & 20 & Estudante \\
\hline 26 & Savannah & Querido John & $* \star *$ & ** & Feminino & 28 & Publicitária \\
\hline 27 & Sebald & Vertigem & ** & ** & Masculino & 52 & Administrador \\
\hline 28 & Sininho & Peter Pan & $\star \star$ & * & Feminino & 25 & Designer \\
\hline 29 & Sira & O Tempo Entre Costuras & 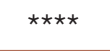 & 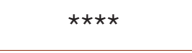 & Feminino & 74 & Psicanalista \\
\hline 30 & Sofia & O Mundo de Sofia & $\star \star \star *$ & 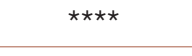 & Feminino & 18 & Estudante \\
\hline 31 & Teodora & Cidades Invisíveis & 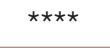 & $\star \star \star *$ & Feminino & 45 & Publicitária \\
\hline 32 & Tistu & O Menino do Dedo Verde & ** & 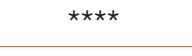 & Masculino & 51 & Publicitário \\
\hline 33 & Winston & 1984 & $\star \star$ & * & Masculino & 53 & Engenheiro \\
\hline
\end{tabular}

Fonte: Preparado pelas autoras. 
A análise dos dados seguiu processo indutivo, com temas emergentes dos dados, sem o apoio de estrutura teórica a priori, e foi realizada ao longo de todo o período da pesquisa de campo. Os dados coletados foram analisados num processo iterativo. À medida que os dados foram coletados e transcritos, analisamos o texto para atribuir códigos e identificar padrões temáticos - categorias. Atribuímos códigos a cada trecho e repetimos o processo diversas vezes. A identificação das categorias integrou dados e teoria (Gibbs, 2008; Gill, 2014; Smith et al., 2009; Tracy, 2010). A introspecção foi usada como subsídio para análise de dados, mas não como dado, recurso que ajuda na triangulação para garantia do rigor científico.

\section{ACHADOS DA PESQUISA}

O ambiente do varejo proporciona múltiplas experiências (Sherry, 1998), que só se realizam no encontro entre o consumidor e as ofertas da empresa, materializadas nos pontos de contato (Thompson, 2004). Como a subjetividade do consumidor pressupõe variações, imprevistos e irracionalidades, a cocriação da experiência tem resultados individualizados, como mostram os achados da pesquisa que apresentamos a seguir, organizados em duas partes, explorando as características pessoais que influenciam a experiência e apresentando os tipos de experiência que emergem das lojas física e virtual.

\section{Influência das características pessoais}

Começamos pela apresentação de dois participantes diferentes, destacando suas preferências em relação a leitura e materialidade do livro e da loja, para situar suas experiências em relação a outros participantes e direcionar a discussão.

Poliana é nutricionista, formada em comunicação e professora universitária com título de doutora, e publicou três livros, um de receitas e dois na área de saúde. Leitora voraz, lê literatura técnica por obrigação e romances por lazer, não escolhe best-sellers porque aprecia histórias complexas, que exijam reflexão. Adora descobrir livrarias novas, prefere lojas pequenas, mas também frequenta as grandes e fica muito tempo olhando os livros, pede recomendações para o vendedor e compra um livro por vez. Compra sempre na livraria física, se não tiver o título que procura, encomenda e vai até a loja buscar, nunca se desfaz de seus livros, e a sala de sua casa é uma biblioteca, com livros em toda parte. Viaja frequentemente, leva muitos livros nas viagens e recentemente começou a usar Kindle para não carregar peso, mas não gosta e o usa apenas nas viagens. Costuma visitar livrarias em outros países, mas raramente compra livros estrangeiros porque prefere ler em português.

Winston é engenheiro e trabalha na área de suprimentos. Frequenta livrarias grandes localizadas em shopping centers da mesma forma que visita lojas de eletroeletrônicos sofisticados, dá uma olhada para saber o que tem de novidade enquanto aguarda sua mulher fazer compras. Lê apenas livros técnicos, que compra em versão digital pela internet, mas compra livros de papel na livraria física, se for presente. Enquanto a visita para dar uma olhada na livraria é feita sem pressa, quando tem o objetivo de comprar um presente a visita é rápida, vai diretamente falar com o vendedor, pega o livro, paga e sai o mais rápido possível, porque tem a impressão de estar perdendo tempo. Não gosta de guardar papéis porque ficam amarelados com o tempo, então digitalizou todos os diplomas e apostilas que tinha em casa e organizou por temas, o que facilita o acesso ao conteúdo e deixa a leitura mais confortável porque pode ajustar o tamanho da letra e a cor do fundo. 
As características pessoais de Poliana e Winston levam a experiências diferentes de livraria e extremos opostos na percepção de relevância da loja física; para Poliana, a livraria física é essencial, mas, para Winston, é dispensável. Nosso estudo mostra que é a combinação de duas características pessoais que define a percepção de relevância e papel da livraria física para cada consumidor: apreço pela leitura e apego à materialidade. Os participantes da pesquisa apresentam intensidades variadas dessas características (ver Quadro 1), em um contínuo de apreço pela leitura que varia de leitores apaixonados a leitores indiferentes (o estudo não inclui participantes não leitores) e um contínuo de apego à materialidade que varia de fortemente apegado a desapegado ao mundo físico.

Chamamos de leitores apaixonados os participantes da pesquisa que, como Poliana, consideram que a leitura é parte fundamental de suas identidades, se orgulham da condição de leitores, carregam sempre um livro e gostam muito de visitar a livraria. Enquanto esperava um dos participantes para a entrevista, no café da Livraria Cultura, a primeira autora observava um homem em pé, perto de uma estante, folheando um livro e com três outros debaixo do braço; alguns minutos depois do horário da entrevista, ele foi apressado até o caixa, comprou quatro exemplares, dirigiu-se ao café, apresentou-se e ofereceu um dos livros para a pesquisadora como presente, enquanto se desculpava pelo atraso, dizendo que não conseguia entrar numa livraria sem comprar livros. A anotação do diário da pesquisadora dizia que, antes mesmo de iniciar a entrevista, sabia que Camilo seria um leitor apaixonado.

Chamamos de leitores indiferentes os participantes que, como Winston, têm uma relação mais utilitária com a leitura, que leem principalmente para se informar ou adquirir algum aprendizado técnico e para quem o prazer não vem da leitura em si, mas do conhecimento que a leitura proporciona. Os seis participantes desse grupo dizem que têm pouco tempo para ler, como explica Sininho: "Atualmente é difícil inserir [a leitura] na rotina, quando você vê, está no Netflix, está cansado e já vai dormir, então o livro vai ficando de lado”. Todos frequentam livrarias esporadicamente, gostam de procurar livros interessantes e desfrutar do ambiente calmo, mas não consideram a visita à livraria um dos seus programas prediletos. Alonso, por exemplo, selecionou o local da entrevista pela qualidade do café servido, preferindo uma padaria ao café da livraria próxima, o que fez as pesquisadoras desconfiarem de que tinha pouca ligação emocional com o mundo dos livros. No exercício de fotoelicitação, Alonso trouxe imagens de exposição de produtos, como alimentos e roupas, e fotos da exposição de livros na livraria, para argumentar que a organização da livraria é confusa, equiparando o livro a outras categorias de produto, o que inicialmente frustrou as pesquisadoras, mas foi essencial na estruturação da análise.

Entre leitores apaixonados e indiferentes, os dois extremos do contínuo, estão os participantes que têm ligação mediana com o universo dos livros. Quanto mais próximo do extremo apaixonado está o participante, mais emocionais e direcionadas ao universo da leitura são suas respostas às ofertas e maior a importância atribuída às experiências da livraria. Quanto mais próximo do extremo indiferente, mais racionais e direcionadas ao ambiente suas respostas e menor a importância atribuída às experiências da livraria. No horário de almoço de dias de semana, quando a loja fica cheia de pessoas que trabalham nas proximidades, observamos consumidores caminhando vagarosamente entre as estantes, olhos fixos nos livros, absorvidos na leitura de trechos; esses são os que mais apreciam a leitura. Outros caminham rapidamente pelo espaço da livraria, procuram um lugar para sentar e ficam entretidos com o celular; são os que têm menor ligação com a leitura. Embora todos estejam desfrutando da experiência da livraria, as experiências são diferentes e ressoam com intensidades diferentes.

Outra característica pessoal que influencia o papel da loja física no varejo contemporâneo, que combina os ambientes físico e virtual, é o apego à materialidade. No livro, os participantes com maior apego à materia- 
lidade relatam apreciação táctil do objeto, formato, peso, tipo de papel, fonte e cheiro, e, principalmente, uma familiaridade com o livro de papel na prática de leitura; na loja, relatam o prazer de estarem cercados por livros e desfrutarem da atmosfera. É como se a materialização de suas individualidade e valores (Ferreira \& Scaraboto, 2016), a extensão de suas identidades (Belk, 1988) e o apego ao lugar (Lewicka, 2011) estivessem não na singularização de objetos (Kopytoff, 1986) e lugares específicos, mas em toda uma categoria. Para fins de análise, consideramos essa característica também como um contínuo, simplificando a complexa combinação de diferentes variáveis relacionadas às alternativas virtual e física de canal e produto: intensidade de preferência, adoção efetiva, razões para adoção e valor da experiência, e identificamos participantes em variadas posições. Iracema, que lê apenas livros físicos e compra apenas em livrarias físicas, é o exemplo extremo de forte apego à materialidade, enquanto Winston, que lê livros digitais e compra pela loja virtual, é o exemplo extremo de desapego à materialidade. Entre esses dois extremos, estão, por exemplo, Melanie, que lê apenas livros físicos e compra pelo canal virtual, Elizabeth, que prefere livros físicos, compra pelo canal virtual e retira o livro na loja física, Clarita, que prefere livro e canal físicos, mas eventualmente adota o livro virtual pelo preço e conveniência, e Rubem, que lê livros físicos e virtuais, prefere a loja física, mas utiliza também o canal virtual. Com exceção de Iracema, todos os participantes transitam entre as dimensões físicas e virtual para comprar e consumir livros, consideram que são experiências diferentes e dizem preferir a loja e o livro físico às opções digitais.

Figura 1. Tipologia da percepção da loja física pelo consumidor

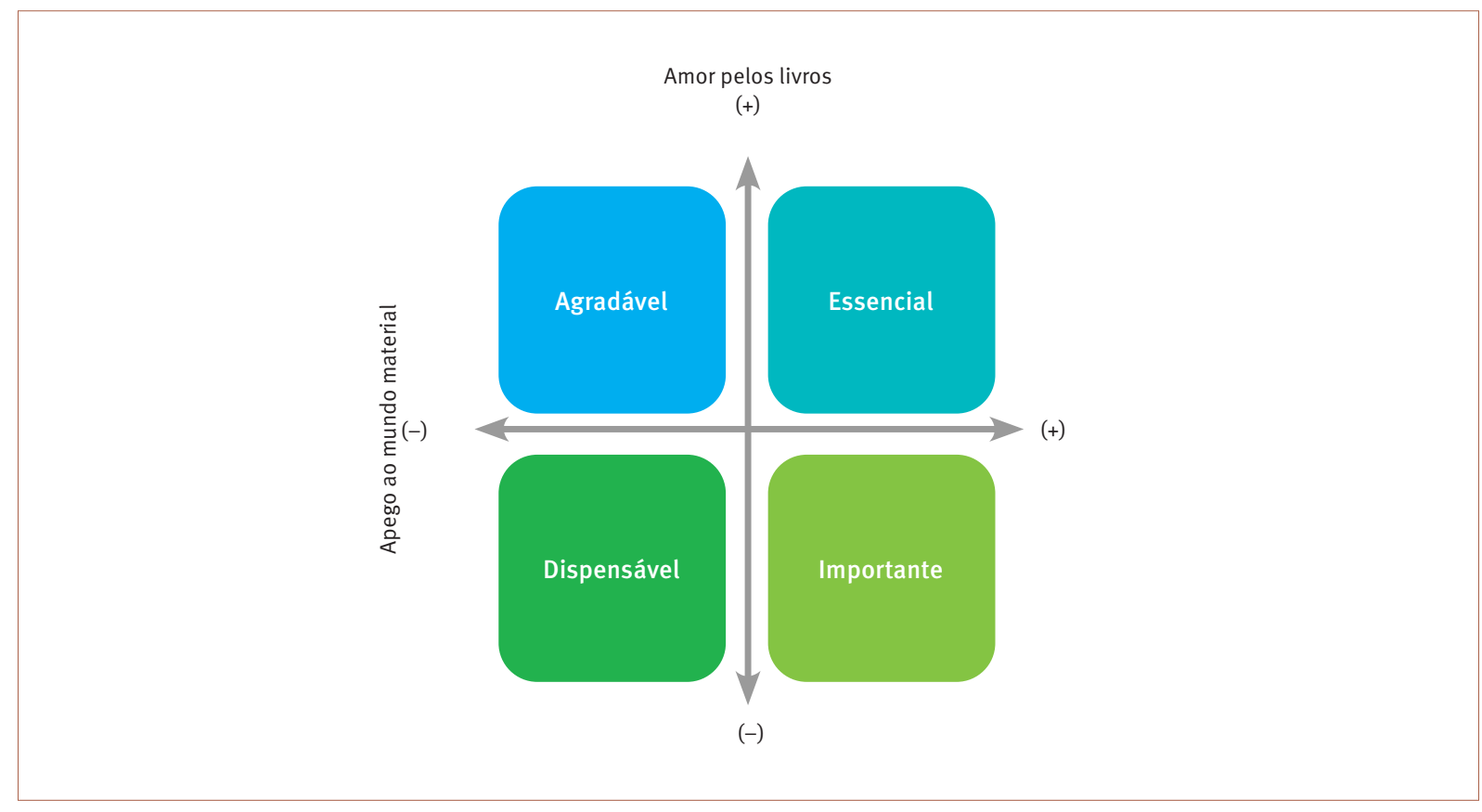

Fonte: Preparado pelas autoras.

A combinação de apreço pela leitura e apego à materialidade leva a entendimentos diversos sobre o papel da loja física, como mostra a Figura 1. As características de Poliana e Winston fazem com que atribuam graus de relevância à loja física muito distintos - essencial para Poliana e dispensável para Winston. Para participantes com apreço regular pela leitura e forte apego à materialidade, como Alonso, a loja é importante. Ele tem pouco tempo para ler, compra livros técnicos na área de Finanças e Contabilidade sempre na versão física e não tem o 
hábito de comprar pela internet. Para participantes como Lúcia, com grande apreço pela leitura e pouco apego à materialidade, a loja é agradável e funciona como showroom. Ela prefere livros físicos, mas lê e-books e transita entre os ambientes físico e virtual para realizar a compra, escolhendo o título na loja física, pesquisando preços pelo celular e comprando onde o preço for melhor. Essas características pessoais não são estáticas, o apreço pela leitura pode variar com mudanças de vida, como Teodora, que foi uma leitora apaixonada, mas hoje está mais distante da leitura, ou Fitz, que descobriu a leitura há pouco tempo, e o apego à materialidade vem diminuindo para diversos participantes, como Emília e Melanie, que passam a adotar as versões virtuais de livro e loja por conveniência, praticidade ou preço.

A literatura salienta o caráter emocional e subjetivo da experiência (Schmitt, 2009), e nossa análise reforça a concepção de que a experiência é formatada pelas histórias, valores, necessidades, sonhos e fantasias do consumidor, portanto é diferente para cada um. Os dados da pesquisa mostram que contextos com maior envolvimento emocional disponibilizam recursos culturais mais atrativos, resultando em experiências de maior ressonância para o consumidor. A seguir, apresentamos os quatro tipos de experiência da livraria identificados na pesquisa.

\section{Tipos de experiência do consumidor}

Estabelecemos que cada consumidor vivencia as experiências diferentemente porque características pessoais específicas resultam em respostas diferentes às ofertas da empresa, influenciando a relevância da loja física. Mostramos agora os tipos de experiência que emergem do encontro de consumidores com o conjunto de ofertas cristalizadas na loja. Neste estudo, identificamos quatro tipos de experiência da livraria: Refúgio do Lar, Portal da Magia, Garimpo e Lugar de Comprar, e percebemos que, enquanto a loja física proporciona todas as quatro experiências, a livraria virtual proporciona apenas as duas últimas. Descrevemos, em seguida, os quatro tipos de experiência emergentes de livrarias.

\section{Lugar de Comprar}

Lugar de Comprar é a experiência funcional, que ocorre em lojas de qualquer segmento quando o consumidor tem o objetivo claro de fechar uma compra rapidamente. A experiência do consumidor na livraria é descrita na literatura como hedônica em todas as ocasiões, variando em função do modelo mental do consumidor, criativo ou funcional (Addis, 2016), porém os dados deste estudo mostram que a experiência do consumidor na livraria depende do apreço pela leitura e pode ser hedônica ou funcional. Em livrarias, essa experiência é ancorada em fatores objetivos, como preço e praticidade, além de prazo de entrega na livraria virtual ou localização na livraria física. A visita de Winston a uma livraria física próxima a sua casa para comprar um livro de presente para a mãe é um exemplo de experiência funcional Lugar de Comprar, como ele conta: "No caso de um presente, que você sabe exatamente o que é, a percepção que você não pode perder muito tempo dentro da livraria é maior. Então eu já entro e já pergunto [para o vendedor]. Eu quero tal livro, e já compro e saio".

A experiência Lugar de Comprar é frequente na loja virtual, que oferece facilidades que podem compensar a perda de uma experiência mais significativa na loja física, mesmo para os consumidores que gostam de ir à loja apenas para passear, como conta Hermione: “Também compro livro on-line, mas eu gosto de ir à livraria comprar, pela experiência de ler. [...] quando eu quero comprar um livro específico e não tenho tanta pressa para recebê-lo, eu compro pela internet porque vou receber em casa”. Esse tipo de experiência, representada pelas imagens de produtos de diferentes categorias trazidas por Alonso no exercício de fotoelicitação, é a mais objetiva das quatro que emergem da livraria. 


\section{Garimpo}

Garimpo é a experiência do consumidor que se entusiasma pela busca do item de valor especial escondido dentro de um conjunto de itens semelhantes. A necessidade de selecionar uma opção interessante entre vários títulos aparece na ilustração de um coração e uma erva espinhosa que Michael produziu para o exercício de fotoelicitação. Na livraria, a experiência de garimpo é originada pela escolha do livro e é associada a uma compra hedônica, que proporciona prazer (Alba \& Williams, 2013), como Camilo explica: “Uma caça, literalmente é uma caça, e tem todo o prazer que a caça proporciona [...]. É prazeroso todo o processo de rastrear o livro". Todos os participantes da pesquisa têm o hábito de visitar a livraria para ver as novidades e tentar identificar uma preciosidade, mas utilizam diversas estratégias para selecionar um título, mesclando as dimensões física e virtual; uma estratégia comum, na internet ou loja física, é começar por um gênero ou autor conhecido e expandir a busca, mas, como conta Rubem, a loja física propicia uma experiência mais orgânica, que possibilita descobertas inesperadas:

Para eu ir da literatura estrangeira até a parte de cozinha, eu tenho que andar. Quando eu estou on-line [...] tenho que saber sempre o que eu quero. Aqui eu posso entrar sem saber o que eu quero mesmo. Então, eu não sei o que eu quero, eu vou andando sem rumo, eu acho. On-line não dá para andar sem rumo.

Alguns participantes, como Lúcia, complementam a pesquisa na internet com uma visita à loja, como ela explica: "A loja física, para mim, acaba servindo mais para pesquisa, para eu ver e manusear o livro, ver o tipo de capa que é, o tipo de papel que é, que tipo de edições existem daquele livro". Depois de escolher, Lúcia utiliza o celular para pesquisar preços, ainda dentro da loja física, e compra onde estiver mais barato, praticando showrooming (Verhoef et al., 2007), prática em que a tecnologia móvel confere mais poder e controle ao consumidor, como prevê a literatura (Labrecque, Esche, Mathwick, Novak, \& Hofacker, 2013).

\section{Refúgio do Lar}

Refúgio do Lar é a experiência proporcionada por um espaço tranquilo, que oferece sensação de segurança, familiaridade, aconchego e abrigo contra um mundo exterior caótico. Tistu, por exemplo, descreve a livraria de shopping que frequenta como um espaço de descompressão que ajuda a aliviar o estresse de fazer compras, sentimento representado pela colagem contrapondo o metrô em movimento, representando o caos do mundo exterior, e as prateleiras da livraria representando calma e segurança, que Michael traz no exercício de fotoelicitação. Para Lúcia, a livraria proporciona segurança; tendo mudado para a cidade há dois meses, passa o tempo livre numa livraria próxima de sua casa, em um ambiente que descreve como agradável, silencioso e conhecido, em que é possível ficar como se estivesse em casa. Para Camilo, a livraria traz um sentido de pertencimento:

[...] é um lugar tranquilo, um lugar bom de se estar de se refletir. Eu faço das livrarias um point, normalmente. Por exemplo: quando eu estou em São Paulo, eu trabalho na Paulista para várias empresas. Cheguei quinze minutos mais cedo, dá tempo de tomar um café na livraria, sentar e ler. [...] a livraria tem essas lounges, tem esses espaços que são de bem-estar, agradáveis. Eu me sinto em casa em qualquer livraria do mundo. 
Nesse tipo de experiência, a livraria assume papel semelhante ao do lar, um espaço de bem-estar emocional (Belk, Seo, \& Li, 2007) que provê conforto e segurança (Roster, Ferrari, \& Jurkat, 2016). Como as livrarias têm atmosfera de quietude e calma, oferecem proteção e oportunidade para relaxamento e socialização para todo a comunidade, são semelhantes a third places (Oldenberg \& Brisset, 1982), porém a literatura estabelece que, por serem locais em que a prioridade dos frequentadores não é socialização, em que a fruição se dá, prioritariamente de modo individual, livrarias não são third places, embora o café dentro da livraria possa aproximar a livraria de third place (Laing \& Royle, 2013).

\section{Portal da Magia}

Em Portal da Magia, a livraria é percebida como passagem entre o mundo normal e um mundo mágico que fica dentro dos livros, como o buraco do coelho no qual Alice cai (Carroll, 2018) ou o velho guarda-roupa que Lucy e seus irmãos atravessam para chegar a Nárnia (Lewis, 2012). Recorrente na literatura fantástica, o portal é uma passagem rumo ao desconhecido, um mundo onde tudo pode acontecer, metáfora para transformação e liminaridade (Gennep, 1960). A livraria, por ser o lugar dos livros e reunir grande quantidade de títulos, funciona como esse lugar suspenso entre o mundo cotidiano e as mil possibilidades de mundos imaginários ou não, onde novos conhecimentos são acessados por meio da leitura. A experiência da livraria é mágica porque aproxima o consumidor de poderes transformadores (Arnould, Price, \& Otnes, 1999) ao permitir acesso ao livro, que tem características de fetiche - objeto com poderes extraordinários que transforma e expande o sentido de self (Fernandez \& Ladowicka, 2011) por meio do conhecimento e imaginação.

Para Emanuel, a atratividade da livraria está ligada à variedade de livros: “[Tem] opções de conteúdo, de imagens, de histórias, de coisas interessantes em geral. Ali você vê os livros mais variados, todas as cores, todos os tamanhos, todos os acabamentos [...] livro descontraído, livro mais sério, livro decorativo, filosófico. Tem de tudo."

O poder transformador do livro está na fala de Príncipe: "você se desliga também um pouco do mundo real, para assumir e entrar junto com o personagem, chegar a outro ponto de vista"; de Melanie: "pode conter uma viagem, contém sentimentos, contém pensamentos [...] te leva para lugares que você jamais iria conhecer dentro da imaginação de alguém"; e de Teodora: "eu acredito que o livro e a literatura trazem para as pessoas a questão de você sonhar, de imaginar coisas que ainda não existem, mas que podem existir”. A imagem do filme Instersection, selecionada por Lúcia, que mostra uma infinidade de espaços e tempos com ares tecnológicos, e a imagem de um garoto entrando em um ambiente iluminado por um portal, selecionada por Michael, representam essa experiência.

\section{DISCUSSÃO}

Nosso estudo investiga a experiência do consumidor no varejo em processo de desmaterialização para revelar mais detalhes sobre o papel da loja física. 0 conceito experiência do consumidor é ancorado na ideia de cocriação e define que a experiência emerge das respostas do consumidor às ofertas da empresa, cristalizadas nos pontos de contato (Lemon \& Vehoef, 2016; Thompson, 2004); nosso estudo, realizado no contexto de livrarias, constata que cada consumidor responde às ofertas de maneira distinta e estabelece que a contribuição do consumidor na cocriação da experiência depende de suas características pessoais, de modo que cada consumidor vivencia uma experiência individualizada. A seguir, detalhamos os achados da pesquisa. 


\section{Experiência individualizada}

A literatura estabelece que o conceito experiência do consumidor foca as respostas do consumidor às ofertas da empresa (Lemon \& Verhoef, 2016), ressaltando que a experiência não é controlada pela empresa (Prahalad \& Ramaswamy, 2004) porque só se realiza quando o consumidor usufrui de suas ofertas, portanto a experiência emerge da interação, nos pontos de contato, de consumidor e empresa, sendo cocriada por ambos. Para a literatura, numa visão centrada no consumidor, o varejo é fonte de múltiplos recursos culturais que são mobilizados pelos consumidores para realizar projetos de vida, combinando esses recursos potenciais com seus próprios recursos, como tradições e valores (Thompson, 2004). Como cada consumidor tem projetos e recursos únicos, a experiência que emerge nos pontos de contato da interação entre empresa e consumidor é individualizada.

\section{Relevância da loja depende dos significados da experiência}

Sendo a experiência individualizada para cada consumidor e emergente das interações nos pontos de contato, cada um tem uma experiência única, e um mesmo consumidor pode ter experiências diferentes em pontos de contato e situações diversas. Embora as respostas de cada consumidor possam variar em interações diferentes num mesmo ponto de contato, os significados atribuídos ao conjunto de suas experiências de consumo em cada ponto de contato tendem a ser próximas. A atribuição e a transferência de significados pelo consumidor ocorrem pela reflexão sobre a experiência vivida e a seleção de recursos, entre os oferecidos pelo mercado, que mais contribuam para a realização de seus projetos (Thompson, 2004). Concluímos, pela identificação de padrões durante a análise de dados, que as características pessoais definem os significados atribuídos e a relevância do ponto de contato. Na livraria, identificamos que a relevância da loja física aumenta quando o consumidor tem apreço pela leitura e apego à materialidade. Muitos dos participantes da pesquisa declaram que apenas recentemente passaram a comprar pela internet e consumir livros digitais, e é razoável imaginar que, à medida que familiaridade dos consumidores com o consumo digital aumente e as empresas invistam para tornar a dimensão virtual mais imersiva e interessante, como os espaços virtuais estudados por Denegri-Knott e Molesworth (2010), a percepção de relevância da loja física se modifique.

\section{Quatro tipos de experiência na loja física e apenas dois na loja virtual}

Identificamos quatro tipos de experiência na interação dos consumidores com os canais de venda em nosso estudo: Refúgio do Lar, Lugar da Magia, Garimpo e Lugar de Compras. A literatura estabelece que o modelo mental do consumidor define o caráter da experiência, que é hedônica se conduzida por consumidores com modelo mental de curiosidade, quando é alavancada por interações com pessoas, e funcional se conduzida por pessoas com modelo mental de planejamento, alavancada por interações com a tecnologia (Addis, 2016). Nosso estudo difere, sugerindo que a definição da experiência da livraria como hedônica ou funcional é, prioritariamente, dada pelas características pessoais dos consumidores; o modelo mental no momento da compra tem importância secundária.

As experiências Lugar de Comprar e Garimpo são relacionadas com a busca e aquisição do produto e ocorrem em diferentes arranjos da jornada de compras: apenas na loja física, apenas na loja virtual ou numa combinação entre as duas. A literatura descreve o empoderamento do consumidor pela tecnologia (Labrecque et al., 2013; Verhoef et al., 2017), e nossa pesquisa confirma mais controle e segurança na compra com a com- 
binação das dimensões física e virtual, especialmente quando há engajamento concomitante nos dois canais no momento da compra e quando a pesquisa virtual é realizada dentro da loja física. Em Lugar de Comprar e Garimpo, a experiência é de controle.

As experiências Refúgio do Lar e Portal da Magia só acontecem na loja física, são ancoradas pela atmosfera da loja, pela presença dos livros e pelo contato com os vendedores, têm caráter hedônico e evocam diversão, sentimentos e fantasia (Holbrook \& Hirschman, 1982). Na literatura, a livraria física é considerada uma loja incomum, com algumas características de third place (Addis, 2016; Laing \& Royle, 2013), e nosso estudo identifica na livraria também elementos que compõem o conceito de lar, como quietude, calma, bem-estar, proteção, segurança e sociabilização (Belk et al., 2007; Oldenberg \& Brisset, 1982; Roster et al., 2016), expressos na experiência Refúgio do Lar. A experiência Portal da Magia, relacionada ao poder transformador da leitura, é ancorada nos livros, objetos mágicos que possibilitam contato com realidades alternativas que proporcionam prazer e aprendizado. $O$ hábito de levar crianças para visitar livrarias com o intuito de incentivar a leitura, prática moralmente valorizada, evoca esse poder transformador originado não nas forças da natureza (Arnould et al., 1999), mas nas forças do conhecimento e criatividade humanos. Em Refúgio do Lar e Portal da Magia, a experiência é de acolhimento e transcendência.

\section{Contribuições, limitações e direcionamentos}

Nosso estudo contribui para a literatura acadêmica sobre experiência do consumidor, ampliando a noção de cocriação da experiência ao estabelecer que a experiência de cada consumidor é única, e contribui para a literatura de varejo, estabelecendo que a relevância da loja é determinada pelas características pessoais do consumidor e confirmando empiricamente que o engajamento em ambos os canais, físico e virtual, no processo de seleção e compra do produto leva ao empoderamento do consumidor. A compreensão dos fatores que determinam a relevância da loja física pode ajudar na gestão do varejo integrado, fornecendo subsídios para adequação do modelo de loja e das ofertas ao perfil desejado de clientes e na definição de investimento em tecnologias de dados e design que individualizem a experiência da loja física (Linzbach et al., 2019) e aperfeiçoem a experiência da loja virtual (Denegri-Knott \& Molesworth, 2010; Mardon \& Belk, 2018).

Como é próprio da pesquisa qualitativa, os achados de nossa pesquisa não são generalizáveis, mas inerentes às livrarias, segmento que é particularmente afetado pela transformação digital e que proporciona experiência singular porque o livro tem alta carga simbólica. Entretanto, acreditamos que as reflexões provocadas por este estudo podem prover indícios sobre a experiência de consumo contemporânea de maneira geral; nos parece que a intensidade do apego ao mundo material é importante para determinar a relevância da loja física em qualquer segmento e que lojas de produtos de qualquer segmento podem propiciar experiências semelhantes a Garimpo e Portal da Magia, se houver especial apreço à categoria de produtos comercializada. Roupas, acessórios e maquiagem podem ter o poder transcendente de tornar o consumidor mais seguro e atraente, material esportivo pode produzir encantamentos para o consumidor ser campeão, acessórios culinários podem transformar magicamente consumidores em artistas da cozinha. Uma oportunidade de pesquisa futura é inquerir se os mesmos critérios para determinação de relevância da loja física podem ser aplicados a outros segmentos e verificar se há variações para categorias de produtos com diferentes distanciamentos do self estendido (Belk, 1988, 2014).

Nosso estudo mostra que as mudanças na livraria são inexoráveis. A loja física, anteriormente o principal ponto de contato entre empresa e consumidor, torna-se, com a desmaterialização do consumo, um entre vários 
pontos de contato. Para sobreviver, o varejo precisa oferecer experiências significativas integrando os canais digital e físico com consistência ao longo de toda a jornada. Este estudo foi desenvolvido com a esperança de que o livro continue encantando leitores, as diversas experiências da livraria ressoem nos consumidores e a livraria física resista.

\section{NOTA}

Este artigo foi apresentado na II International Social Networks Conference em 2019, promovida pelo Centro de Excelência em Varejo da Fundação Getulio Vargas, Escola de Administração de Empresas de São Paulo.

\section{REFERÊNCIAS}

Addis, M. (2016). Understanding the customer journey to create excellent customer experiences in bookshops. International Journal of Marketing Studies, 8(4), 20. doi:10.5539/ijms. v8n4p2o

Addis, M., \& Holbrook, M. (2001). On the conceptual link between mass customisation and experiential consumption: An explosion of subjectivity. Journal of Consumer Behaviour, 1(1), 50-66. doi:10.1002/cb.53

Alba, J., \& Williams, E. (2013). Pleasure principles: A review of research on hedonic consumption. Journal of Consumer Psychology, 23(1), 2-18. doi: 10.1016/j.jcps.2012.07.003

Almeida, C. (2017, julho 6). Experiência não paga a conta. Exame. Recuperado de https://exame.abril.com.br/negocios/herzda-cultura-experiencia-nao-paga-conta/

Arnould, E. (2005) Animating the big middle. Journal of Retailing, 81(2), 89-96. doi:10.1016/j.jretai.2005.03.001

Arnould, E., Price, L., \& Otnes, C. (1999). Making magic consumption: A study of white-water river rafting. Journal of Contemporary Ethnography, 28(1), 33-68. doi:10.1177/089124199129023361

Arsel, Z. (2017). Asking questions with reflexive focus: A tutorial on designing and conducting interviews. Journal of Consumer Research, 44(4), 939-948. doi:10.1093/jcr/ucxo96

Atasoy, O., \& Morewedge, C. K. (2018). Digital goods are valued less than physical goods. Journal of Consumer Research, 44(6), 1343-1357. doi:10.1093/jcr/ucx102

Aubrey, C., \& Judge, D. (2012). Re-imagine retail: Why store innovation is key to a brand's growth in the 'new normal', digitally-connected and transparent world. Journal of brand strategy, 1(1), 31-39.

Babin, B., Darden, W., \& Griffin, M. (1994). Work and/or fun: Measuring hedonic and utilitarian shopping value. Journal of Consumer Research, 20(4), 644-656. doi:10.1086/209376
Bardhi, F., \& Eckhardt, G. M. (2012). Access-based consumption: The case of car sharing. Journal of Consumer Research, 39(4), 881-898. doi: 10.1086/666376

Bardhi, F., \& Eckhardt, G. M. (2017). Liquid consumption. Journal of Consumer Research, 44(3), 582-597. doi:10.1093/jcr/ucx050

Belk, R. (1988). Possessions and the extended self. Journal of Consumer Research, 15(2), 139-168. doi:10.1086/209154

Belk, R. (2014). You are what you can access: Sharing and collaborative consumption online. Journal of Business Research, 67(8), 1595-1600. doi:10.1016/j. jbusres.2013.10.001

Belk, R., Seo, Y., \& Li, E. (2007). Dirty little secret: Home chaos and professional organizers. Consumption Markets \& Culture, 10(2), 133-140. doi: 10.1080/10253860701256208

Carroll, L. (2018). Alice no País das Maravilhas. São Paulo, SP: Sesi-SP.

Carù, A., \& Cova, B. (2003). Revisiting consumption experience: A more humble but complete view of the concept. Marketing Theory, 3(2), 267-286. doi:10.1177/14705931030032004

Coffman, C. (2018, June 19) Shops aren’t for shopping anymore. The Atlantic. Recuperado de https://www.theatlantic.com/ TECHNOLOGY/ARCHIVE/2018/06/SHOPS-ARENT-FORSHOPPING-ANYMORE/563054/?UTM_SOURCE=ATLFB

Corkery, M. (2018, September 3) Hard lessons (Thanks Amazon) breath new life into retail stores. The New York Times. Recuperado de https://www.nytimes.com/2018/09/03/ business/retail-walmart-amazon-economy.html

DeLanda, M. (2006). A new philosophy of society: Assemblage theory and social complexity. London, UK: Continuum.

Denegri-Knott, J., \& Molesworth, M. (2010). Concepts and practices of digital virtual consumption. Consumption, Markets and Culture, 13(2), 109-132. doi:10.1080/10253860903562130 
Denegri-Knott, J., Watkins, R., \& Wood, J. (2013). Transforming digital goods into meaningful possessions. Digital Virtual Consumption, 23(76), 83-98. 10.4324/9780203114834

Exame. (2018, outubro 25). Livraria Cultura pede recuperação judicial em meio à crise do mercado. Recuperado de https://exame.abril.com.br/negocios/livraria-cultura-pederecuperacao-judicial-em-meio-a-crise-do-mercado/

Fernandez, K., \& Lastovicka, J. (2011). Making magic: Fetishes in contemporary consumption. Journal of Consumer Research, 38(2), 278-299. doi:10.1086/659079

Ferreira, M., \& Scaraboto, D. (2016). "My plastic dreams": Towards an extended understanding of materiality and the shaping of consumer identities. Journal of Business Research, 69(1), 191-207. doi:10.1016/j.jbusres.2015.07.032

Gennep, A. van. (1960) The rites of passage (M. B. Vizedom \& G. L. Caffe, Trans.). London, UK: Routledge and Kegan Paul.

Gensler, S., Neslin, S., \& Verhoef, P. (2017). The showrooming phenomenon: It's more than just about price. Journal of Interactive Marketing, 38, 29-43. doi:10.1016/j.intmar.2017.01.003

Gibbs, G. R. (2008). Analysing qualitative data: The Sage qualitative research kit. Newbury Park, USA: Sage.

Gill, M. J. (2014). The possibilities of phenomenology for organizational research. Organizational Research Methods, 17(2), 118-137. doi:10.1177/1094428113518348

Giovanelli, C. (2016, março 21). Cultura fecha 2 de suas 4 lojas no Conjunto Nacional. Veja SP. 21/03/2016. Recuperado de https://vejasp.abril.com.br/consumo/livraria-cultura-conjunto-nacional-fechou-lojas/

Hirschman, E., \& Horlbrook, M. (1982). Hedonic consumption: Emerging concepts, methods and propositions. The Journal of Marketing, 46(3), 92-101. doi:10.1177/002224298204600314

Hoffman, D. L., \& Novak, T. P. (2017). Consumer and object experience in the internet of things: An assemblage theory approach. Journal of Consumer Research, 44(6), 1178-1204. doi:10.1093/jcr/ucx105

Holbrook, M. (2018). Essay on the origins, development, and future of the consumption experience as a concept in marketing and consumer research. Qualitative Market Research: An International Journal, 21(4), 421-444. doi: 10.118/QMR-04-2018-0041

Holbrook, M., \& Hirschman, E. (1982, September). The experiential aspects of consumption: Consumer fantasies, feelings, and fun. Journal of Consumer Research, 9, 132-140. doi:10.1086/208906

Holbrook, M. B. (2000). The millennial consumer in the texts of our times: Experience and entertainment. Journal of Macromarketing, 20(2), 178-192. doi:10.1093/jcr/ucx105

Kopytoff, I. (1986). The cultural biography of things: Commoditization as process. In A. Appadurai, The social life of things: Commodities in cultural perspective (pp. 64-91). Cambridge, UK: Cambridge University Press.

Kozinets, R. (2019). Consuming technocultures: An extended JCR curation. Journal of Consumer Research, 46(3), 620-627. doi:10.1093/jcr/uczo34
Kozinets, R., Patterson A., \& Ashman, R. (2017). Networks of desire: How technology increases our passion to consume. Journal of Consumer Research, 43(5), 659-682. doi:10.1093/ jcr/ucwo61

Labrecque, L., Esche, J. vor dem, Mathwick, C., Novak, T., \& Hofacker, C. (2013). Consumer power: Evolution in the digital age. Journal of Interactive Marketing, 27(4), 257-269. doi:10.1016/j.intmar.2013.09.002

Laing, A., \& Royle, J. (2013). Examining chain bookshops in the context of "third place". International Journal of Retail \& Distribution Management, 41(1), 27-44. doi:10.1108/09590551311288157

Lehdonvirta, V. (2012). A history of the digitalization of consumer culture: From Amazon through Pirate Bay to FarmVille. Digital virtual consumption (pp. 11-28). New York, USA: Routledge.

Lemon, K., \& Verhoef, P. (2016). Understanding customer experience throughout the customer journey. Journal of Marketing, 8o(6), 69-96. doi:10.1509/jm.15.0420

Lewicka, M. (2011). Place attachment: How far have we come in the last 40 years? Journal of Environmental Psychology, 31(3), 207-230. doi:10.1016/j.jenvp.2010.10.001

Lewis, C. S. (2012). As crônicas de Nárnia, São Paulo, SP: Martins Fontes.

Linzbach, P., Inman, J. J., \& Nikolova, H. (2019). E-Commerce in a physical store: Which retailing technologies add real value? NIM Marketing Intelligence Review, 11(1), 42-47. Recuperado de https://www.proquest.com/ openview/cb0379f1589a5bo62951ec75661819aa/1?pqorigsite $=$ gscholar $\& \mathrm{cbl}=756365$

Livraria Cultura. (2017). Quem somos. Recuperado de https:// www.livrariacultura.com.br/quem-somos

Magaudda, P. (2011). When materiality 'bites back': Digital music consumption practices in the age of dematerialization. Journal of Consumer Culture, 11(1), 15-36. doi:10.1177/1469540510390499

Mardon, R., \& Belk, R. (2018). Materializing digital collecting: An extended view of digital materiality. Marketing Theory, 18(4), 543-570. doi:10.1177/1470593118767725

Melo, A. (2018, junho 13). Cultura fecha Fnac de Pinheiros, em SP, primeira loja da rede no país. Valor Econômico. Recuperado de https://www.valor.com.br/empresas/5593585/culturafecha-fnac-de-pinheiros-em-sp-primeira-loja-da-rede-no-pais

Oldenburg, R., \& Brissett, D. (1982). The third place. Qualitative Sociology, 5(4), 265-284. doi:10.1007/BFoog86754

Pine, B., \& Gilmore, J. (1998). Welcome to the experience economy. Harvard Business Review, 76, 97-105. Recuperado de https://is.muni.cz/el/econ/jaro2020/ MKR_PRCR/98252981/Pine_Gilmore_Welcome_to_the Experience_Economy.pdf

Pine, B., \& Gilmore, J. (1999). The experience economy: Work is theatre \& every business a stage. Cambridge, UK: Harvard Business Press. 
Prahalad, C. K., \& Ramaswamy, V. (2004). Co-creation experiences: The next practice in value creation. Journal of Interactive Marketing, 18(3), 5-14. doi:10.1002/dir.20015

Roster, C., Ferrari, J., \& Jurkat, M. (2016). The dark side of home: Assessing possession 'clutter' on subjective wellbeing. Journal of Environmental Psychology, 46, 32-41. doi:10.1016/jenvp.2016.03.003

Rushe, D. (2017, July 23). Big, bold ... and broken: Is the US shopping mall in a fatal decline? The Guardian. Recuperado de https://www.theguardian.com/us-news/2017/jul/22/ mall-of-america-minnesota-retail-anniversary

Schmitt, B. (2009) The concept of brand experience. Journal of Brand Management, 16, 417-419. doi:10.1057/bm.2009.5

Schmitt, B. (2011). Experience marketing: Concepts, frameworks and consumer insights. Foundations and Trends $₫$ in Marketing, 5(2), 55-112. doi:10.1561/1700000027

Schmitt, B., Brakus, J., \& Zarantonello, L. (2015). From experiential psychology to consumer experience. Journal of Consumer Psychology, 25(1), 166-171. doi:10.1016/jcps.2014.09.001

Schmitt, B., Rogers, D., \& Vrostsos, K. (2004). There's no business that's not show business: Marketing in an experience culture. New Jersey, USA: Financial Times Press.

Shankar, V., Inman, J., Mantrala, M., Kelley, E., \& Rizley, R. (2011). Innovations in shopper marketing: Current insights and future research issues. Journal of Retailing, 87, S29-S42. doi:10.1016/j.jretai.2011.04.0007

Sherry, J. (1998). Understanding markets as places: An introduction to servicescapes. In J. Sherry (Ed.), Servicescapes: The concept of place in contemporary markets (pp. 1-24). Chicago, USA: NTC.

Smith, J., Flowers, P., \& Larkin, M. (2009). Interpretative phenomenological analysis: Theory, method and research. London, UK: Sage.
Thompson, C., Locander, W., \& Pollio, H. (1989). Putting consumer experience back into consumer research: The philosophy and method of existential-phenomenology. Journal of Consumer Research, 16(2), 133-146. doi:10.1086/209203

Thompson, C. J. (2004). Marketplace mythology and discourses of power. Journal of Consumer Research, 31(1), 162-180. doi:10.1086/383432

Tracy, S. J. (2010). Qualitative quality: Eight "big-tent" criteria for excellent qualitative research. Qualitative Inquiry, 16(10), 837-851. doi:10.1177/1077800410383121

Verhoef, P., Kannan, P., \& Inman, J. (2015). From Multi-channel retailing to omni-channel retailing: Introduction to the special issue on multi-channel retailing, Journal of Retailing, 91(2), 174-181. doi:10.1016/j.jretai.2015.02.005

Verhoef, P., Neslin, S., \& Vroomen, B. (2007). Multichannel customer management: Understanding the researchshopper phenomenon. International Journal of Research in Marketing,24(2),129-148. doi:10.1016/j.ijresmar.2006.11.002

Verhoef, P., Stephen, A., Kannan, P., Luo, X., Abhishek, V., Andrews, M., ... Hu, M. M. (2017). Consumer connectivity in a complex, technology-enabled, and mobile-oriented world with smart products. Journal of Interactive Marketing, 40, 1-8. doi:10.1016/j.intmar.2017.06.001

Wallendorf, M., \& Belk, R. W. (1989). Assessing trustworthiness in naturalistic consumer research. In E. Hirschman (Ed.), Interpretative consumer research (ACR Special Volumes, pp. 69-84). Provo, USA: Association for Consumer Research.

Wallendorf, M., \& Brucks, M. (1993). Introspection in consumer research: Implementation and implications. Journal of Consumer Research, 20(3), 339-359. doi:10.1086/209354

\section{CONTRIBUIÇÃO DAS AUTORAS}

Maria Silvia Moliterno Pena e Eliane Pereira Zamith Brito trabalharam na conceitualização e abordagem teórica-metodológica. A revisão teórica foi conduzida por Maria Silvia Moliterno Pena. A coleta de dados foi coordenada por Maria Silvia Moliterno Pena. Participaram da análise de dados Maria Silvia Moliterno Pena e Eliane Pereira Zamith Brito. Maria Silvia Moliterno Pena e Eliane Pereira Zamith Brito participaram da redação e revisão final do manuscrito. 